\title{
Variable utility in the enigmatic presence of ultraviolet reflectance in conspicuous aposematic signals
}

\author{
Justin Yeager ${ }^{1}$ and James Barnett ${ }^{2}$ \\ ${ }^{1}$ Universidad de Las Américas \\ ${ }^{2}$ McMaster University
}

June 29, 2021

\begin{abstract}
Warning signals are often characterized by highly contrasting, distinctive and memorable colors. Both chromatic (hue) and achromatic (brightness) contrast contribute to signal efficacy, making longwave colored signals (red and yellow) that generate both chromatic and achromatic contrast common. Shortwave colors (blue and ultraviolet) do not contribute to luminance perception, yet are also common in warning signals. The presence of UV aposematic signals is paradoxical as UV perception is not universal, and evidence for its utility is at best mixed. We used visual modeling to quantify how UV affects signal contrast in aposematic butterflies and frogs. We found that UV only appreciably affected visual contrast in the butterflies. As the butterflies, but not the frogs, have UV-sensitive vision these results support the notion that UV reflectance is associated with intraspecific communication, but appears to be non-functional in frogs. Consequently, we should be careful when assigning a selection-based benefit from UV reflectance.
\end{abstract}

\section{Introduction:}

Our contemporary understanding of the evolution of bright and conspicuous color patterns is rooted in the work of the early pioneers of evolutionary themes such as natural selection. Charles Darwin developed the theory of sexual selection to explain the presence of conspicuous ornamentation, but realised it could not account for the presence of bright colors in non-reproductive Lepidopteran larvae (Darwin 1871). Alfred Russel Wallace, on the other hand, was skeptical of sexual selection and instead built on the work of John Jenner Weir and Henry Walter Bates, to outline a theory of aposematic warning signals, that was later developed further by Edward Bagnall Poulton (Caro 2017; Caro and Ruxton 2019; Marchant 1916; Poulton 1890).

Aposematic and sexually selected color patterns are highly diverse, but such signals are often characterised by high visual contrast both between pattern components within an organism, and to the background against which the organism is viewed (Andersson 1994; Ruxton et al. 2019; Stevens and Ruxton 2012). Brighter and more conspicuous signals are commonly associated with more potent defences and greater reproductive fitness, such that predators are more easily deterred (Aronsson and Gamberale-Stille 2008; Forsman and Herrström 2004; Forsman and Merilaita 1999; Halpin et al. 2020; Prudic et al. 2006; Stevens et al. 2010), rivals are more wary, and potential mates more interested when signals are highly contrasting (Andersson 1994; Endler 1983; Ryan and Keddy-Hector 1992; Svensson and Wong 2011).

High signal contrast can be achieved via two interconnected visual pathways: achromatic contrast (luminance/brightness) and chromatic contrast (hue/saturation). In vertebrates, achromatic contrast is measured as a single intensity value received by longwave sensitive photoreceptors, whereas hue is perceived through opponent processing by two or more photoreceptors that differ in their peak wavelength sensitivity (Kelber and Osorio 2010; Vorobyev and Osorio 1998). Consequently, different colors contribute to phenotypic 
contrast in different ways: longwave colors (e.g., red, orange, and yellow) contribute to both achromatic and chromatic contrast, whereas shortwave colors (e.g., blue and ultraviolet (UV)) only significantly affect chromatic contrast (Stevens and Ruxton 2012; Umbers 2013).

For this reason, conspicuous signals frequently generate high visual contrast by combining bright long wavelength colors with low luminance black (Stevens and Ruxton 2012). Short wavelength colors, including UV, can also create high contrast and are occasionally incorporated into seemingly conspicuous signals (Umbers 2013). However, evidence for the efficacy of UV in aposematic signals has been mixed, with no compelling confirmation that naturally occurring UV signals are effective at deterring predators despite some evidence that UV signals can be learned (Lyytinen et al. 2001; Werner et al. 2014a; Werner et al. 2014b; Werner et al. 2012). Moreover, rather than preventing attacks UV containing (UV+) signals can instead deflect attacks to more expendable body parts (Olofsson et al. 2010), or they may actually increase predation risk (Lyytinen et al. 2004). Despite the discovery of UV reflectance attracting much attention, perhaps due to our own inability to perceive such signals, we currently lack a complete understanding of if, or to what extent, UV reflectance contributes to aposematic signaling.

In the Neotropics two independent, and completely unrelated, radiations of bright conspicuous colors have drawn much scientific attention: the heliconiian butterflies (Heliconiinae; Nymphalidae) and the poison frogs (Dendrobatidae: Anura). Both groups are found in similar rainforest habitats, are highly toxic, are at risk from similar predatory taxa, and have become renowned for their high diversity of species and bright colors (Merrill et al. 2015; Stynoski et al. 2015).

Despite many similarities in color diversity, chemical defense, the visual environment, and the predator community, ultraviolet reflective colors are relatively common in heliconiian butterflies but seemingly rare in poison frogs (Briscoe et al. 2010; Bybee et al. 2012; Yeager and Barnett 2020). Indeed, we recently described the first example of UV-reflectance in poison frogs, from an Ecuadorian population ofOophaga sylvatica. We found that although UV shows up brightly in photographs, it adds little to internal color pattern contrast (Yeager and Barnett 2020). As coloring in both groups has been selected under the influence of similar UV-sensitive predators for the purpose of aposematism, the lack of UV reflection in frogs is perplexing. Here we expand these previous findings to describe UV reflectance in two more species of poison frog (Ameerega bilinguis and Epipedobates tricolor ). We compare the contribution of UV to signal contrast between these two dendrobatid frogs and five species of heliconiian butterflies, and then discuss the importance of predator versus conspecific vision to point to potential explanations for the evolution of UV reflectance in these groups.

\section{Methods:}

Study systems

The heliconiian butterflies, especially the specious Genus Heliconius, have been extensively studied in relation to color patterns that both warn predators of their potent toxins and signal important identifying information to conspecifics (Merrill et al. 2015). Complex mimicry systems have evolved to exploit predator avoidance learning and subtle visual cues are used by conspecifics to identify potential mates (Bybee et al. 2012; Dell'Aglio et al. 2018; Merrill et al. 2015). The butterflies are potential prey to a diversity of predators, including insectivorous birds and lizards, many of which have vision sensitive to UV reflectance (Dell'Aglio et al. 2018). Similarly, the butterflies themselves are also able to see ultraviolet with some species having evolved two UV sensitive photoreceptors that allow for fine scale discrimination of UV wavelengths (Briscoe et al. 2010; Finkbeiner and Briscoe 2020). For example female Heliconius eratohave a functionally pentachromatic (cone peak sensitivities $\left(\lambda_{\max }\right)$ of $355 \mathrm{~nm}, 390 \mathrm{~nm}, 470 \mathrm{~nm}, 555 \mathrm{~nm}$, and $600 \mathrm{~nm}$ ) visual system (McCulloch et al. 2016). The evolution of a duplicate UV-sensitive opsins is constrained to the genus Heliconius and appears to have co-evolved with the presence of specific UV-reflecting yellow pigments which are predicted to be important in directing both intra- and interspecific behaviors (Briscoe et al. 2010).

Poison frogs have similarly become a model system for understanding the interplay between aposematic and sexually selected signals (Stynoski et al. 2015). Brighter and more contrasting colors offer greater protection from predators (Dreher et al. 2015; Maan and Cummings 2012), are more intimidating to rivals (Crothers 
et al. 2011; Crothers and Cummings 2015; Galeano and Harms 2016), and are favored by potential mates (Dreher et al. 2017; Maan and Cummings 2008; Maan and Cummings 2009). Poison frogs, like heliconiian butterflies, are at risk from a wide range of UV-sensitive predators, including birds, snakes, and lizards (Alvarado et al. 2013; de Lanuza and Font 2014; Dreher et al. 2015; Lenger et al. 2014; Maan and Cummings 2012; Master 1998; Santos and Cannatella 2011; Saporito et al. 2007; Siddiqi et al. 2004; Willink et al. 2013). However, unlike the butterflies, poison frogs are not known to possess UV-sensitive vision. The one well described poison frog visual system being that of Oophaga pumilio, which has trichromatic vision $\left(\lambda_{\max }\right.$ of $466 \mathrm{~nm}, 489 \mathrm{~nm}$, and $561 \mathrm{~nm}$ ) that both lacks a UV-sensitive cone and has a lens that filters out UV wavelengths (Siddiqi et al. 2004; Yovanovich et al. 2020).

\section{Photography}

We photographed two species of Neotropical poison frog (Ameerega bilinguis and Epipedobates tricolor "Cielito" morph, Dendrobatidae) and five species of Neotropical aposematic butterfly (Eueides isabella, Heliconius atthis, H. erato ,H. ismenius, and two subspecies of H. melpomene, Nymphalidae). The frogs $($ A. bilinguis $=5 ;$ E. tricolor $=4)$ were photographed at the WIKIRI Selva Viva / Centro Jambatu (Quito, Ecuador) and the butterflies $(E$. isabella $=4, H$. atthis $=2, H$. erato $=2, H$. ismenius $=2, H$. melpomene aglaope $=2, H$. melpomene plessen $=2$ ) were photographed at the Mariposas de Mindo - Butterfly Garden (Mindo, Ecuador). We also refer to recently published data on a UV reflective population of $O$. sylvatica ("Lita" morph), that was photographed in the wild (Yeager and Barnett 2020).

To capture reflectance values across an ecologically relevant spectrum, we took calibrated photographs in both human visible (VIS $=\sim 400-700 \mathrm{~nm})$ and ultraviolet wavelengths $(\mathrm{UV}=\sim 300-400 \mathrm{~nm}$ ), following methods outlined in Yeager and Barnett (2020). In short, we took all digital images using a tripod mounted, UVsensitive, full spectrum quartz converted Canon EOS 7D that was combined with a metal body NIKKOR EL $80 \mathrm{~mm}$ lens. For human-visible spectra we fitted the lens with a Baader UV-IR blocking filter (allowing transmission of 420-680 nm), and for the UV photographs we fitted a Baader UV pass filter (allowing transmission of 320-380 $\mathrm{nm}$ ). We photographed each subject in both human visible and UV wavelengths, under natural downwelling illumination that was representative of the covered canopy forests where both butterflies and frogs occur. All images were saved in RAW format and included a $10 \%$ and a $77 \%$ reflectance standard that allowed for color calibration and scaling.

\section{Image processing}

We used the MICA toolbox in ImageJ v1.52k to linearize, align, and combine our paired VIS and UV photographs into a series of multispectral images (Schneider et al. 2012; Troscianko and Stevens 2015). We used the $10 \%$ and $77 \%$ reflectance standards to linearize the images, and each of the photo pairs were aligned manually. We then manually selected regions of interest (ROIs), from each multispectral image, by selecting up to six of the strongest UV reflecting regions (UV+), and up to six similarly sized and shaped adjacent regions that did not reflect UV (UV-).

For the butterflies, we selected ROIs from the undersides of both the forewings and hindwings as these regions will be visible to both predators and conspecifics, and where most species had the greatest UV reflectance. In the frogs, the location of the UV reflecting regions was more variable but was limited to dorsal, lateral and inguinal regions which would similarly be visible to avian predators. All ROIs were also chosen to avoid regions of specular reflectance (see Figure 1 for species-specific UV reflection regions).

\section{Visual modeling}

To investigate how the presence of UV reflectance affects visual contrast between adjacent UV+ and UVregions we compared the responses of a UV-sensitive visual model to those of a VIS-sensitive visual model (Troscianko and Stevens 2015; Yeager and Barnett 2020). These models were both generated using the UV sensitive, tetrachromatic, vision of the Eurasian blue tit (Cyanistes caeruleus, Paridae), which has single cone $\lambda_{\max }$ of $573 \mathrm{~nm}$ (LWS), $508 \mathrm{~nm}$ (MWS), $413 \mathrm{~nm}$ (SWS), $372 \mathrm{~nm}$ (UVS), and double cones with $\lambda_{\max }$ of $565 \mathrm{~nm}$ (D) (Hart et al. 2000). The UV-sensitive model included the LWS, MWS, SWS, and UVS cones 
spanning 300-700 nm, whereas the VIS-sensitive model used the LWS, MWS, and SWS cones (excluding the UVS cone), to cover 400-700 $\mathrm{nm}$. We also included the response of the D cone in both visual models.

We converted each multispectral image into relative cone capture rates using the MICA toolbox in ImageJ v1.52k (Schneider et al. 2012; Troscianko and Stevens 2015). Visual contrast was calculated as 'just noticeable differences' (JNDs) using the receptor-noise-limited model (Vorobyev and Osorio 1998). A JND of 1 represents the theoretical visual discrimination threshold below which two colors cannot be distinguished (Vorobyev and Osorio 1998). Conversely, JNDs $>3$ are increasingly more easily discernable (Vorobyev and Osorio 1998). We calculated chromatic (hue) contrast from the responses of the single cones and calculated achromatic (luminance) contrast from the response of the double cone (Hart et al. 2000; Vorobyev and Osorio 1998). In both cases, we used Weber fractions of 0.05 (Hart et al. 2000; Troscianko and Stevens 2015; Vorobyev and Osorio 1998). We hypothesized that if UV reflectance is an important component of the signal, chromatic contrast would be perceivably higher in the UV-sensitive model than is the VIS-sensitive model (Yeager and Barnett 2020).

\section{Results}

We found that in all instances visual contrast between adjacent UV + and UV-color patches was high, with JND values well above the conservative discrimination threshold $(\mathrm{JND}=3$, Table 1$)$. However, when comparing between UV-sensitive and VIS-sensitive models, we found that although achromatic contrast was nearly identical between the two models, there were differences in chromatic contrast (Table 1). For all comparisons chromatic contrast was higher in the UV-sensitive model, although the magnitude of the effect varied by taxa. Moreover, when considering each species/subspecies individually we found that the magnitude of the difference between UV and VIS models was very high for butterflies but comparatively low for frogs in both relative and absolute terms (Figure 1, Table 1).

\section{Discussion}

We found that our sample of heliconiian butterflies and poison frogs all reflected detectable quantities of ultraviolet light. When comparing between VIS and UV sensitive visual models, this UV reflectance had a negligible effect on achromatic contrast but did affect chromatic contrast, to varying degrees. The visual signals of heliconiian butterflies and poison frogs have both evolved under the influence of UV sensitive predators for the purpose of mitigating predation risk via aposematism. However, we found that UV reflectance from butterfly color patterns had a much greater effect on enhancing chromatic contrast, both in terms of absolute (change in JNDs) and proportional (percent increase due to the addition of UV) change, than was recorded from the color patterns of either of the poison frog species.

Maximizing visual contrast is not necessarily the goal of aposematic signals, and two patterns can be visually distinct (e.g., different combinations of colors) while being equally contrasting. However, by quantifying the contribution of UV to achromatic and chromatic contrast, our approach allows us to estimate the relative importance of these wavelengths to signal design. That said, it is important to note that the presence of UV reflectance within a color pattern does not equate to UV serving an explicit function; and depending on context UV reflectance could act as aposematism, camouflage, sexual signaling, thermoregulation, or protection from solar radiation (Umbers 2013). Moreover, pigments and structural colors will interact with light beyond the wavelengths visible to observers, and reflectance characteristics outside of the visible range may evolve without direct selection. For example, selection for very high reflectance across 400-700 nm would very plausibly, as a byproduct, also produce significant reflectance in the near ultraviolet $(350-400 \mathrm{~nm})$ and perhaps near infrared $(700-750 \mathrm{~nm})$.

We cannot, therefore, definitively state a function for ultraviolet reflectance in poison frogs, if indeed there is a function. However, by directly comparing the characteristics of frog coloring to the well-known UV signals of heliconiian butterflies we can provide guidance for future investigations.

Many heliconiian butterflies have evolved highly contrasting signals that contain a significant amount of UV light. However, despite high contrast, and likely being visible to potential predators, UV reflectance 
does not appear to play an important role in predator aversion (Dell'Aglio et al. 2018; Finkbeiner et al. 2017). The most compelling selection-based explanation for the evolution of UV+ signals comes from their potential use(s) for sexual selection in the genusHeliconius, where UV+ 3-hydroxy-DL-kynurenine (3-OHK) yellow pigments coincide with the duplication of UVS opsin genes (Briscoe et al. 2010). These signals have, therefore, co-evolved with complex UV sensitive visual systems that allow heliconiian butterflies to tune into UV reflectance for both mate choice and species recognition (Briscoe et al. 2010; Bybee et al. 2012; Finkbeiner et al. 2014; Finkbeiner et al. 2017). Visual discrimination that potentially plays an important role in preventing intergeneric hybridization between mimetic Heliconiusand Eueides butterflies (Finkbeiner et al. 2017). Whereas all Heliconius species have duplicated UV coding opsin genes, it is only likely truly influencing vision in certain clades ofHeliconius (such as H. erato, UV contrast shown in Figure 1E), yet even in these clades, expression is sex-specific and benefits apparently restricted to females (Finkbeiner and Briscoe 2020; McCulloch et al. 2016).

In comparison, UV reflectance in poison frogs appears to only have a small effect on pattern contrast, and its utility, if any, remains unknown (Yeager and Barnett 2020). Preliminary findings do not suggest UV in A. bilinguis inguinal flash marks enhances detection with model human predators (McEwan personal communication). Although color can be an important intra-specific signal for poison frogs (Maan and Cummings 2009; Yang et al. 2019) the lack of UV sensitive photoreceptors in the dendrobatid visual system means that it is unlikely that ultraviolet reflectance has evolved in response to mating preferences or intraspecific recognition. Importantly, however, visual perception has only be characterized for O. pumilio (Siddiqi et al. 2004), a species that lacks UV reflectance (Chaves-Acuña et al. 2020; Maan and Cummings 2009; Siddiqi et al. 2004; Summers et al. 1999). Therefore, although it may be unlikely, we cannot conclusively rule out the presence of UV sensitive vision in other dendrobatid species. Moreover, as strong UV reflectance does not appear to affect predation risk in artificial targets (Lyytinen et al. 2001) or heliconiian butterflies (Finkbeiner et al. 2017), it also seems improbable that the comparatively weak UV reflectance observed in poison frogs would be an important contribution to aposematic signals. Indeed, where UV reflectance has been reported in poison frogs other color pattern combinations that lack UV have actually been found to result in greater visual contrast (Yeager and Barnett 2020), and are more likely to be avoided by avian predators (Lawrence and Noonan 2018).

To fully understand UV coloring in poison frogs we believe further study is required. Firstly, we believe that it is important to characterize the visual systems of a greater diversity of dendrobatid species considering the impressive diversity of intra- and inter-specific color patterns, where some species reflect UV and many wellstudied species apparently do not. Secondly, behavioral trials both with potential predators and conspecifics are needed to examine whether observers respond differently to UV+ and UV- signals under natural lighting conditions. More widely, we believe that the role of UV reflectance in aposematic signaling deserves more attention, or perhaps publication bias against non-significant findings needs to be addressed. Finally, we caution about the over interpretation of function in animal coloration, such as in UV signals, and specifically suggest that neutral evolutionary processes may be more common in shaping animal color patterns than currently acknowledged.

Here we investigated the degree to which UV reflectance affected the visual contrast of conspicuous signals. UV is known to play an important role in intra-specific communication in heliconiian butterflies, and we found that UV had a correspondingly large effect on increasing the chromatic contrast of butterfly coloration. Conversely, poison frogs are not known to perceive UV light, and UV reflectance had a comparatively small effect on signal contrast. These data support the notion that UV reflectance does not necessarily have a special role in aposematic signal design and has likely evolved neutrally in many poison frogs (Yeager and Barnett 2020), however, much remains unknown.

\section{ACKNOWLEDGMENTS}

We thank the Ministerio del Ambiente, Ecuador, for research per- mission (Permit Number: 014-2019-ICFLO-DNB/MA) and the Universidad de Las Americas, Quito, Ecuador, for financial support (Grant Number: FGE.JY.20.13). 


\section{Data Availability Statement}

Data have been deposited in Dryad https://datadryad.org/stash/share/TTJXGEF6y2UlFRjTrl2HyFMX4Nzl3mDdekiGWZ5

\begin{tabular}{|c|c|c|c|c|c|c|c|c|}
\hline & & & $\begin{array}{l}\text { Chromatic } \\
\text { Contrast }\end{array}$ & $\begin{array}{l}\text { Chromatic } \\
\text { Contrast }\end{array}$ & & $\begin{array}{l}\text { Achromatic } \\
\text { Contrast }\end{array}$ & $\begin{array}{l}\text { Achromatic } \\
\text { Contrast }\end{array}$ & \\
\hline & & $\begin{array}{l}\text { VIS } \\
\text { Model }\end{array}$ & $\begin{array}{l}\text { UV } \\
\text { Model }\end{array}$ & $\begin{array}{l}\text { Difference } \\
(\%)\end{array}$ & & $\begin{array}{l}\text { VIS } \\
\text { Model }\end{array}$ & $\begin{array}{l}\text { UV } \\
\text { Model }\end{array}$ & $\begin{array}{l}\text { Differe } \\
(\%)\end{array}$ \\
\hline Poison & Poison & Poison & Poison & Poison & Poison & Poison & Poison & Poison \\
\hline \multirow[t]{4}{*}{ Frogs } & Frogs & Frogs & Frogs & Frogs & Frogs & Frogs & Frogs & Frogs \\
\hline & $\begin{array}{l}\text { Ameerega } \\
\text { bilinguis }\end{array}$ & $\begin{array}{l}16.40 \pm \\
4.24\end{array}$ & $\begin{array}{l}19.71 \pm \\
2.97\end{array}$ & $\begin{array}{l}3.31 \\
(20.18 \%)\end{array}$ & & $\begin{array}{l}50.63 \pm \\
2.57\end{array}$ & $\begin{array}{l}50.69 \pm \\
2.59\end{array}$ & $\begin{array}{l}0.06 \\
(0.12 \%)\end{array}$ \\
\hline & $\begin{array}{l}\text { Epipedobates } \\
\text { tricolor } \\
\text { (Cielito } \\
\text { morph) }\end{array}$ & $6.21 \pm 0.91$ & $6.87 \pm 1.29$ & $\begin{array}{l}0.66 \\
(10.63 \%)\end{array}$ & & $\begin{array}{l}78.63 \pm \\
4.81\end{array}$ & $\begin{array}{l}78.55 \pm \\
4.87\end{array}$ & $\begin{array}{l}-0.08 \\
(-0.10 \%\end{array}$ \\
\hline & $\begin{array}{l}\text { Oophaga } \\
\text { sylvatica } \\
\text { (Lita } \\
\text { morph) * }\end{array}$ & $\begin{array}{l}24.96 \pm \\
5.05\end{array}$ & $\begin{array}{l}32.39 \pm \\
6.76\end{array}$ & $\begin{array}{l}7.43 \\
(29.77 \%)\end{array}$ & & $\begin{array}{l}26.22 \pm \\
4.29\end{array}$ & $\begin{array}{l}26.45 \pm \\
4.30\end{array}$ & $\begin{array}{l}0.23 \\
(0.88 \%)\end{array}$ \\
\hline Heliconiinae & Heliconiinae & Heliconiinae & Heliconiinae & Heliconiinae & Heliconiinae & Heliconiinae & Heliconiinae & \\
\hline \multirow[t]{7}{*}{ Butterflies } & Butterflies & Butterflies & Butterflies & Butterflies & Butterflies & Butterflies & Butterflies & \\
\hline & $\begin{array}{l}\text { Eueides } \\
\text { isabella }\end{array}$ & $\begin{array}{l}13.47 \pm \\
1.89\end{array}$ & $\begin{array}{l}24.99 \pm \\
0.73\end{array}$ & $\begin{array}{l}11.52 \\
(85.52 \%)\end{array}$ & & $\begin{array}{l}74.30 \pm \\
1.97\end{array}$ & $\begin{array}{l}74.71 \pm \\
1.97\end{array}$ & $\begin{array}{l}0.41 \\
(0.55 \%)\end{array}$ \\
\hline & $\begin{array}{l}\text { Heliconius } \\
\text { atthis }\end{array}$ & $\begin{array}{l}15.28 \pm \\
3.94\end{array}$ & $\begin{array}{l}28.25 \pm \\
1.01\end{array}$ & $\begin{array}{l}12.97 \\
(84.88 \%)\end{array}$ & & $\begin{array}{l}58.26 \pm \\
7.77\end{array}$ & $\begin{array}{l}58.72 \pm \\
7.92\end{array}$ & $\begin{array}{l}0.46 \\
(0.79 \%)\end{array}$ \\
\hline & $\begin{array}{l}\text { Heliconius } \\
\text { erato }\end{array}$ & $6.68 \pm 2.98$ & $\begin{array}{l}20.74 \pm \\
3.98\end{array}$ & $\begin{array}{l}14.06 \\
(210.48 \%)\end{array}$ & & $\begin{array}{l}59.99 \pm \\
9.34\end{array}$ & $\begin{array}{l}60.30 \pm \\
9.37\end{array}$ & $\begin{array}{l}0.31 \\
(0.52 \%)\end{array}$ \\
\hline & $\begin{array}{l}\text { Heliconius } \\
\text { ismenius }\end{array}$ & $\begin{array}{l}36.91 \pm \\
3.48\end{array}$ & $\begin{array}{l}49.50 \pm \\
1.35\end{array}$ & $\begin{array}{l}12.59 \\
(34.11 \%)\end{array}$ & & $\begin{array}{l}37.21 \pm \\
9.38\end{array}$ & $\begin{array}{l}37.37 \pm \\
9.42\end{array}$ & $\begin{array}{l}0.16 \\
(0.43 \%)\end{array}$ \\
\hline & $\begin{array}{l}\text { Heliconius } \\
\text { melpomene } \\
\text { aglaope }\end{array}$ & $5.84 \pm 4.52$ & $\begin{array}{l}12.06 \pm \\
5.88\end{array}$ & $\begin{array}{l}6.22 \\
(106.51 \%)\end{array}$ & & $\begin{array}{l}65.30 \pm \\
6.22\end{array}$ & $\begin{array}{l}65.50 \pm \\
6.28\end{array}$ & $\begin{array}{l}0.20 \\
(0.31 \%\end{array}$ \\
\hline & $\begin{array}{l}\text { Heliconius } \\
\text { melpomene } \\
\text { plessen }\end{array}$ & $7.18 \pm 4.35$ & $\begin{array}{l}15.00 \pm \\
2.68\end{array}$ & $\begin{array}{l}7.82 \\
(108.91 \%)\end{array}$ & & $\begin{array}{l}89.90 \pm \\
4.49\end{array}$ & $\begin{array}{l}90.19 \pm \\
4.40\end{array}$ & $\begin{array}{l}0.29 \\
(0.32 \%)\end{array}$ \\
\hline
\end{tabular}

Table 1. Chromatic and achromatic contrast from the VIS and UV sensitive visual models (JND means \pm $\mathrm{SE}$ ), and the absolute and relative (\%) difference in mean contrast between VIS and UV models (*Oophaga sylvatica (Lita locality) data from Yeager and Barnett (2020)). 


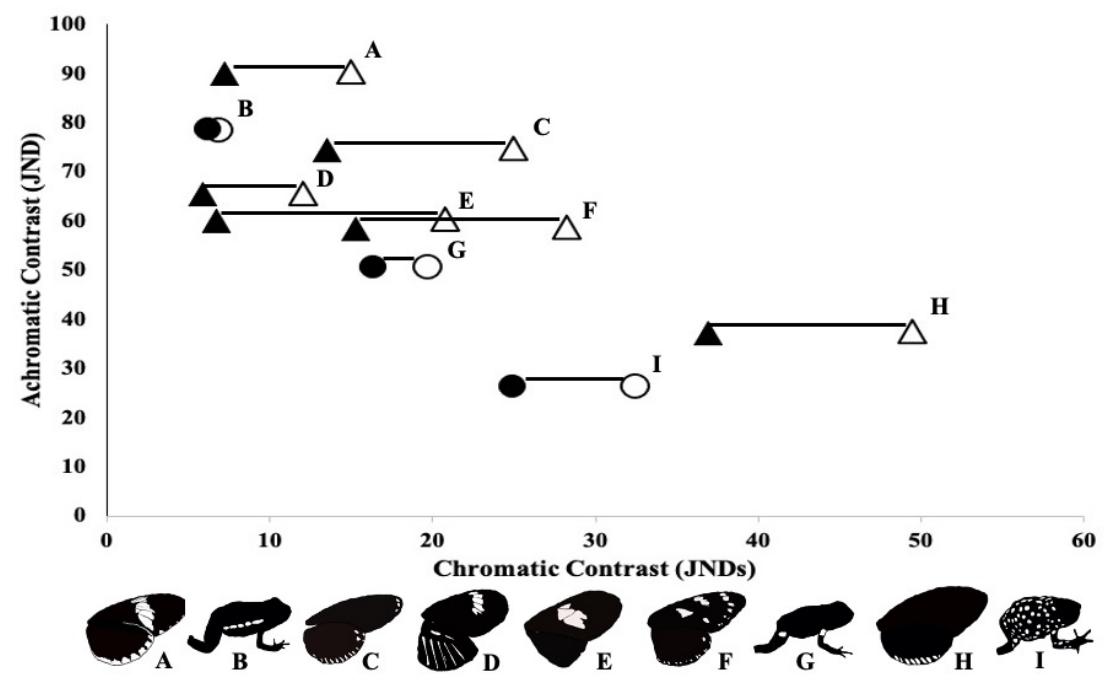

Figure 1: Contrast measured in chromatic and achromatic contrast mean "just noticeable differences" (JNDS) estimated for UV reflecting regions compared against adjacent non-UV reflecting patches as viewed by UV-sensitive models (open symbols) and VIS-sensitive models (filled symbols). Triangles indicate butterfly species and circles poison frog species. In nearly all species UV signals increase chromatic, but not achromatic contrast, but to differing degrees (see Table 1 for specific values and standard errors). Species in order of descending achromatic contrast: $\mathrm{A}=$ Heliconius melpomene plessen, $\mathrm{B}=$ Epipedobates tricolor Cielito, $\mathrm{C}$ $=$ Eueides isabella, $\mathrm{D}=$ Heliconius melpomene agalope, $\mathrm{E}=$ Heliconius erato, $\mathrm{F}=$ Heliconius atthis, $\mathrm{G}$ - Ameerega bilinguis , $\mathrm{H}=$ Heliconius ismenius , and $\mathrm{I}=$ Oophaga sylvatica Lita (from Yeager and Barnett 2020). UV reflecting color pattern regions are shown in white in the silhouette illustrations below.

\section{Literature Cited}

Alvarado, J. B., A. Alvarez, and R. A. Saporito. 2013. Oophaga pumilio (strawberry poison frog) Predation. Herpetological Review 44:298.

Andersson, M. 1994, Sexual selection. Princeton, NJ, USA, Princeton University Press.

Aronsson, M., and G. Gamberale-Stille. 2008. Domestic chicks primarily attend to colour, not pattern, when learning an aposematic coloration. Animal Behaviour 75:417-423.

Briscoe, A. D., S. M. Bybee, G. D. Bernard, F. Yuan, M. P. Sison-Mangus, R. D. Reed, A. D. Warren et al. 2010. Positive selection of a duplicated UV-sensitive visual pigment coincides with wing pigment evolution in $<$ em $>$ Heliconius $</$ em $>$ butterflies. Proceedings of the National Academy of Sciences 107:3628-3633.

Bybee, S. M., F. Yuan, M. D. Ramstetter, J. Llorente-Bousquets, R. D. Reed, D. Osorio, and A. D. Briscoe. 2012. UV Photoreceptors and UV-Yellow Wing Pigments in Heliconius Butterflies Allow a Color Signal to Serve both Mimicry and Intraspecific Communication. The American Naturalist 179:38-51.

Caro, T. 2017. Wallace on Coloration: Contemporary Perspective and Unresolved Insights. Trends in Ecology \& Evolution 32:23-30.

Caro, T., and G. Ruxton. 2019. Aposematism: Unpacking the Defences. Trends in Ecology \& Evolution 34:595-604.

Chaves-Acuña, W., L. Sandoval, P.-P. Bitton, G. Barrantes, and A. García-Rodríguez. 2020. Conspecific and Predator Perception of the Red $<\mathrm{i}>$ Oophaga pumilio $</ \mathrm{i}>$ Morph from the Central Caribbean of Costa Rica. Journal of Herpetology 54:361-370, 310. 
Crothers, L., E. Gering, and M. Cummings. 2011. Aposematic signal variation predicts male-male interactions in a polymorphic poison frog. Evolution 65:599-605.

Crothers, L. R., and M. E. Cummings. 2015. A multifunctional warning signal behaves as an agonistic status signal in a poison frog. Behavioral Ecology 26:560-568.

Darwin, C. 1871, The Decent of Man, and selection in relation to sex. London, UK, John Murray.

de Lanuza, G. P. i., and E. Font. 2014. Ultraviolet vision in lacertid lizards: evidence from retinal structure, eye transmittance, SWS1 visual pigment genes and behaviour. The Journal of Experimental Biology 217:28992909 .

Dell'Aglio, D. D., J. Troscianko, W. O. McMillan, M. Stevens, and C. D. Jiggins. 2018. The appearance of mimetic Heliconius butterflies to predators and conspecifics. Evolution 72:2156-2166.

Dreher, C. E., M. E. Cummings, and H. Pröhl. 2015. An Analysis of Predator Selection to Affect Aposematic Coloration in a Poison Frog Species. PLOS ONE 10:e0130571.

Dreher, C. E., A. Rodríguez, M. E. Cummings, and H. Pröhl. 2017. Mating status correlates with dorsal brightness in some but not all poison frog populations. Ecology and Evolution 7:10503-10512.

Endler, J. A. 1983. Natural and sexual selection on color patterns in poeciliid fishes. Environmental Biology of Fishes 9:173-190.

Finkbeiner, S. D., and A. D. Briscoe. 2020. True UV color vision in a butterfly with two UV opsins. bioRxiv:2020.2011.2014.382507.

Finkbeiner, S. D., A. D. Briscoe, and R. D. Reed. 2014. Warning signals are seductive: Relative contributions of color and pattern to predator avoidance and mate attraction in Heliconius butterflies. Evolution 68:34103420 .

Finkbeiner, S. D., D. A. Fishman, D. Osorio, and A. D. Briscoe. 2017. Ultraviolet and yellow reflectance but not fluorescence is important for visual discrimination of conspecifics by $<$ em $>$ Heliconius erato $</ e m>$. The Journal of Experimental Biology 220:1267-1276.

Forsman, A., and J. Herrström. 2004. Asymmetry in size, shape, and color impairs the protective value of conspicuous color patterns. Behavioral Ecology 15:141-147.

Forsman, A., and S. Merilaita. 1999. Fearful symmetry: pattern size and asymmetry affects aposematic signal efficacy. Evolutionary Ecology 13:131-140.

Galeano, S. P., and K. E. Harms. 2016. Coloration in the polymorphic frog Oophaga pumilio associates with level of aggressiveness in intraspecific and interspecific behavioral interactions. Behavioral Ecology and Sociobiology 70:83-97.

Halpin, C. G., O. Penacchio, P. G. Lovell, I. C. Cuthill, J. M. Harris, J. Skelhorn, and C. Rowe. 2020. Pattern contrast influences wariness in naïve predators towards aposematic patterns. Scientific Reports 10:9246.

Hart, N. S., J. C. Partridge, I. C. Cuthill, and A. T. D. Bennett. 2000. Visual pigments, oil droplets, ocular media and cone photoreceptor distribution in two species of passerine bird: the blue tit (Parus caeruleus L.) and the blackbird (Turdus merula L.). Journal of Comparative Physiology A 186:375-387.

Kelber, A., and D. Osorio. 2010. From spectral information to animal colour vision: experiments and concepts. Proceedings of the Royal Society B: Biological Sciences 277:1617-1625.

Lawrence, J. P., and B. P. Noonan. 2018. Avian learning favors colorful, not bright, signals. PLOS ONE 13:e0194279.

Lenger, D. R., J. K. Berkey, and M. B. Dugas. 2014. Predation on the toxic Oophaga pumilio (Anura: Dendrobatidae) by Rhadinaea decorata (Squamata: Collubridae). Herpetology Notes 7:83-84. 
Lyytinen, A., R. V. Alatalo, L. Lindström, and J. Mappes. 2001. Can ultraviolet cues function as aposematic signals? Behavioral Ecology 12:65-70.

Lyytinen, A., L. Lindström, and J. Mappes. 2004. Ultraviolet reflection and predation risk in diurnal and nocturnal Lepidoptera. Behavioral Ecology 15:982-987.

Maan, M. E., and M. E. Cummings. 2008. Female preferences for aposematic signal components in a polymorphic poison frog. Evolution 62:2334-2345.

-. 2009. Sexual dimorphism and directional sexual selection on aposematic signals in a poison frog. Proceedings of the National Academy of Sciences 106:19072-19077.

- 2012. Poison Frog Colors Are Honest Signals of Toxicity, Particularly for Bird Predators. The American Naturalist 179:E1-E14.

Marchant, J. 1916, Alfred Russel Wallace letters and reminiscences. London, UK, Cassell.

Master, T. L. 1998. Dendrobates auratus (black-and-green poison dart frog) Predation. Herpetological Review 29:164-165.

McCulloch, K. J., D. Osorio, and A. D. Briscoe. 2016. Sexual dimorphism in the compound eye of Heliconius erato : a nymphalid butterfly with at least five spectral classes of photoreceptor. The Journal of Experimental Biology 219:2377-2387.

Merrill, R. M., K. K. Dasmahapatra, J. W. Davey, D. D. Dell'Aglio, J. J. Hanly, B. Huber, C. D. Jiggins et al. 2015. The diversification of Heliconius butterflies: what have we learned in 150 years? Journal of Evolutionary Biology 28:1417-1438.

Olofsson, M., A. Vallin, S. Jakobsson, and C. Wiklund. 2010. Marginal eyespots on butterfly wings deflect bird attacks under low light intensities with UV wavelengths. PLOS ONE 5:e10798.

Poulton, E. B. 1890, The colours of animals. London, UK, Kegan Paul, Trench, Trübner, \& Co. Ltd.

Prudic, K. L., A. K. Skemp, and D. R. Papaj. 2006. Aposematic coloration, luminance contrast, and the benefits of conspicuousness. Behavioral Ecology 18:41-46.

Ruxton, G., W. L. Allen, T. N. Sherratt, and M. P. Speed. 2019, Avoiding attack. Oxford, UK, Oxford University Press.

Ryan, M. J., and A. Keddy-Hector. 1992. Directional Patterns of Female Mate Choice and the Role of Sensory Biases. The American Naturalist 139:S4-S35.

Santos, J. C., and D. C. Cannatella. 2011. Phenotypic integration emerges from aposematism and scale in poison frogs. Proceedings of the National Academy of Sciences 108:6175-6180.

Saporito, R. A., R. Zuercher, M. Roberts, K. G. Gerow, and M. A. Donnelly. 2007. Experimental Evidence for Aposematism in the Dendrobatid Poison Frog Oophaga pumilio . Copeia 2007:1006-1011, 1006.

Schneider, C. A., W. S. Rasband, and K. W. Eliceiri. 2012. NIH Image to ImageJ: 25 years of image analysis. Nature Methods 9:671-675.

Siddiqi, A., T. W. Cronin, E. R. Loew, M. Vorobyev, and K. Summers. 2004. Interspecific and intraspecific views of color signals in the strawberry poison frog Dendrobates pumilio . Journal of Experimental Biology 207:2471-2485.

Stevens, M., J. Mappes, and S.-L. Sandre. 2010. The effect of predator appetite, prey warning coloration and luminance on predator foraging decisions. Behaviour 147:1121.

Stevens, M., and G. D. Ruxton. 2012. Linking the evolution and form of warning coloration in nature. Proceedings of the Royal Society B: Biological Sciences 279:417-426. 
Stynoski, J. L., L. M. Schulte, and B. Rojas. 2015. Poison frogs. Current Biology 25:R1026-R1028.

Summers, K., R. Symula, M. Clough, and T. Cronin. 1999. Visual mate choice in poison frogs. Proceedings of the Royal Society of London. Series B: Biological Sciences 266:2141-2145.

Svensson, P. A., and B. B. M. Wong. 2011. Carotenoid-based signals in behavioural ecology: a review. Behaviour 148:131-189.

Troscianko, J., and M. Stevens. 2015. Image calibration and analysis toolbox - a free software suite for objectively measuring reflectance, colour and pattern. Methods in Ecology and Evolution 6:1320-1331.

Umbers, K. D. L. 2013. On the perception, production and function of blue colouration in animals. Journal of Zoology 289:229-242.

Vorobyev, M., and D. Osorio. 1998. Receptor noise as a determinant of colour thresholds. Proceedings of the Royal Society of London. Series B: Biological Sciences 265:351-358.

Werner, S. J., R. Buchholz, S. K. Tupper, S. E. Pettit, and J. W. Ellis. 2014a. Functional significance of ultraviolet feeding cues in wild turkeys. Physiology \& Behavior 123:162-167.

Werner, S. J., S. T. DeLiberto, S. E. Pettit, and A. M. Mangan. 2014b. Synergistic effect of an ultraviolet feeding cue for an avian repellent and protection of agricultural crops. Applied Animal Behaviour Science 159:107-113.

Werner, S. J., S. K. Tupper, J. C. Carlson, S. E. Pettit, J. W. Ellis, and G. M. Linz. 2012. The role of a generalized ultraviolet cue for blackbird food selection. Physiology \& Behavior 106:597-601.

Willink, B., E. Brenes-Mora, F. Bolaños, and H. Pröhl. 2013. Not everything is black and white: color and behavioral variation reveal a continuum between cryptic and aposematic strategies in a polymorphic poison frog. Evolution 67:2783-2794.

Yang, Y., S. Blomenkamp, M. B. Dugas, C. L. Richards-Zawacki, and H. Pröhl. 2019. Mate Choice versus Mate Preference: Inferences about Color-Assortative Mating Differ between Field and Lab Assays of Poison Frog Behavior. The American Naturalist 193:598-607.

Yeager, J., and J. B. Barnett. 2020. Ultraviolet components offer minimal contrast enhancement to an aposematic signal. Ecology and Evolution 10:13576-13582.

Yovanovich, C. A. M., M. E. R. Pierotti, A. Kelber, G. Jorgewich-Cohen, R. Ibáñez, and T. Grant. 2020. Lens transmittance shapes ultraviolet sensitivity in the eyes of frogs from diverse ecological and phylogenetic backgrounds. Proceedings of the Royal Society B: Biological Sciences 287:20192253. 